\title{
The anterior-to-psoas approach for interbody fusion at the L5-S1 segment: clinical and radiological outcomes
}

\author{
Massimo Miscusi, MD, PhD, ${ }^{1}$ Sokol Trungu, MD, ${ }^{1,2}$ Luca Ricciardi, MD, ${ }^{1,2}$ Stefano Forcato, MD, ${ }^{2}$ \\ Alessandro Ramieri, MD, $\mathrm{PhD},{ }^{3}$ and Antonino Raco, MD, $\mathrm{PhD}^{1}$
}

\begin{abstract}
'Department of Neuroscience, Mental Health, and Sense Organs, "Sapienza" University of Rome, Sant'Andrea Hospital, Rome; ${ }^{2}$ Neurosurgery Unit, Cardinal G. Panico Hospital, Tricase; and ${ }^{3}$ Department of Orthopedics, Faculty of Pharmacy and Medicine, "Sapienza" University of Rome, Italy
\end{abstract}

OBJECTIVE Over the last few decades, many surgical techniques for lumbar interbody fusion have been reported. The anterior-to-psoas (ATP) approach is theoretically supposed to benefit from the advantages of both anterior and lateral approaches with similar complication rates, even in L5-S1. At this segment, the anterior lumbar interbody fusion (ALIF) requires retroperitoneal dissection and retraction of major vessels, whereas the iliac crest does not allow the lateral transpsoas approach. This study aimed to investigate clinical-radiological outcomes and complications of the ATP approach at the L5-S1 segment in a single cohort of patients.

METHODS This is a prospective single-center study, conducted from 2016 to 2019 . Consecutive patients who underwent ATP at the L5-S1 segment for degenerative disc disease or revision surgery after previous posterior procedures were considered for eligibility. Complete clinical-radiological documentation and a minimum follow-up of 12 months were set as inclusion criteria. Clinical patient-reported outcomes, such as the visual analog scale for low-back pain, Oswestry Disability Index, and 36-Item Short Form Health Survey (SF-36) scores, as well as spinopelvic parameters, were collected preoperatively, 6 weeks after surgery, and at the last follow-up visit. Intraoperative and perioperative complications were recorded. The fusion rate was evaluated on CT scans obtained at 12 months postoperatively.

RESULTS Thirty-two patients met the inclusion criteria. The mean age at the time of surgery was 57.6 years (range 44-75 years). The mean follow-up was 33.1 months (range 13-48 months). The mean pre- and postoperative visual analog scale $(7.9 \pm 1.3$ vs $2.4 \pm 0.8, p<0.05)$, Oswestry Disability Index (52.8 \pm 14.4 vs $22.9 \pm 6.0, p<0.05)$, and SF-36 $(37.3 \pm 5.8$ vs $69.8 \pm 6.1, p<0.05)$ scores significantly improved. The mean lumbar lordosis and L5-S1 segmental lordosis significantly increased after surgery. The mean pelvic incidence-lumbar lordosis mismatch and pelvic tilt significantly decreased. No intraoperative complications and a postoperative complication rate of $9.4 \%$ were recorded. The fusion rate was $96.9 \%$. One patient needed a second posterior revision surgery for residual foraminal stenosis.

CONCLUSIONS In the present case series, ATP fusion for the L5-S1 segment has resulted in valuable clinical-radiological outcomes and a relatively low complication rate. Properly designed clinical and comparative trials are needed to further investigate the role of ATP for different L5-S1 conditions.

https://thejns.org/doi/abs/10.3171/2020.6.FOCUS20335

KEYWORDS anterior-to-psoas approach; ATP; oblique lumbar interbody fusion; OLIF; degenerative lumbar diseases; anterior approaches; minimally invasive surgery

$\mathrm{L}$ UMBAR interbody fusion has been progressively identified as the treatment of choice for many conditions affecting the lumbar spine, such as degenerative disc disease (DDD), spondylolisthesis, segmental instability, and deformities. ${ }^{1-4}$ Anterior and lateral approaches, using standard open and minimally invasive surgery techniques, have increased their applications during the last few decades. $^{5-7}$ In anterior and lateral approaches, surgeons are able to use higher, more lordotic, and larger footprint cages, theoretically increasing the chances for achieving fusion, restoring the segmental lordosis and disc height, and indirectly decompressing the vertebral canal. ${ }^{8-11}$

ABBREVIATIONS ALIF = anterior lumbar interbody fusion; ATP = anterior to psoas; DDD = degenerative disc disease; LBP = low-back pain; LLIF = lateral lumbar interbody fusion; ODI = Oswestry Disability Index; OLIF = oblique lumbar interbody fusion; PI-LL = pelvic incidence-lumbar lordosis; SF-36 = 36-Item Short Form Health Survey; VAS = visual analog scale.

SUBMITTED April 29, 2020. ACCEPTED June 10, 2020.

INCLUDE WHEN CITING DOI: 10.3171/2020.6.FOCUS20335. 
Oblique lumbar interbody fusion (OLIF) is an anteriorto-psoas (ATP) approach, performed with the patient in the lateral decubitus position, first described by Mayer in $1997^{12}$ and then modified by Silvestre et al. in $2012 . .^{13} \mathrm{Sev}-$ eral studies have reported OLIF as safe, with acceptable clinical-radiological outcomes and complication rates. ${ }^{14-20}$

For the L5-S1 segment, ATP approaches remain controversial due to the necessity for mobilizing retroperitoneal major vessels and the iliac crest projection on the lower lumbar spine. Therefore, anterior lumbar interbody fusion (ALIF) is still preferred for the lumbosacral junction, due to the straight surgical trajectory to the anterior profile of this segment. On the other hand, conventional open ALIF requires a major retroperitoneal dissection, which may increase risks for vascular and nerve injuries, and thus potential life-threatening hemorrhages and retrograde ejaculation, respectively. ${ }^{21,22}$

Although the mini-ALIF approach may indeed reduce the need for retroperitoneal dissection and retraction, the entire anterior profile has to be exposed for correct placement of the implant. For the L5-S1 segment, in mini-open anterior approaches the supine surgical position of the patient requires a major retraction of abdominal contents, which could be challenging in obese patients. On the other hand, in lateral techniques the viscera fall down due to gravity, which acts as a natural retractor. Furthermore, posterior pedicle screws can be placed percutaneously in the lateral position, whereas a second stage is needed in anterior approaches.

This study aimed to investigate the role of the ATP approach for the L5-S1 segment, evaluating clinical-radiological outcomes and the complication rates in a singlecenter series of patients.

\section{Methods}

\section{Study Design}

This is a single-center prospective cohort study. A dedicated informed consent was released and approved, data were collected and retrieved anonymously for analysis, and the institutional review board approved the present investigation.

\section{Patient Population}

Patients referred to our department between March 2016 and March 2019, suffering from L5-S1 DDD (group A) or kyphotic segmental deformity secondary to previous posterior surgery (group B), were considered for eligibility.

Inclusion criteria for group A were axial low-back pain (LBP) and Pfirrmann grade $>2$; for group B the criteria were axial LBP and pelvic incidence-lumbar lordosis (PI-LL) mismatch $>12^{\circ}$; and the criteria for both groups were complete clinical and radiological documentation, a minimum follow-up of 12 months, and unresponsiveness to conservative management (physiotherapy, injections, medications, and rest) for $\geq 3$ months.

Exclusion criteria were as follows: oncological diagnosis; isthmic spondylolysis; degenerative spondylolisthesis grade $\geq$ II (Meyerding classification ${ }^{23}$ ); severe osteoporosis (T-score $\leq-2.5$ on dual-energy $\mathrm{x}$-ray absorptiometry or presence of fragility fractures as defined by the WHO); recent trauma; and recent history of retroperitoneal surgery.

\section{ATP L5-S1 Surgical Technique}

Every procedure was performed by two experienced senior neurosurgeons (A. Raco and M. Miscusi) and did not involve any access surgeon.

The patient is always placed in the right lateral decubitus position. Fluoroscopy guidance is used to mark the anterior and posterior margins of the L5-S1 disc space. A 5 -cm oblique incision is made approximately $2-3 \mathrm{~cm}$ anterior to the anterior superior iliac spine. Using blunt scissors and smooth dissection techniques, the external oblique, internal oblique, and transverse abdominal muscles are progressively dissected, and then the retroperitoneal space is exposed and dissected using fingers and cotton pads.

Once the psoas muscle is identified, the first blade for retraction is positioned in front of its tendon, constituting the posterior wall of the surgical corridor. The ureter is gently mobilized anteriorly together with the peritoneum contents. Then, a second blade is positioned medially to gently retract the retroperitoneal space and expose the iliac vessels. Particular attention should be dedicated to the left common iliac vein, which may have a different course and relation with the anterior profile of the lumbosacral junction; it is generally found underneath the left common iliac artery. The lateral blade is now moved medial to these vessels, which are gently retracted toward the psoas muscle. The medial blade is finally positioned deeper, over the midline, and it can be fixed by pins to the L5 vertebral body.

There are some anatomical variations and different veins at this segment, especially the segmental vessels and the iliolumbar vein, so careful inspection should be done before final positioning of the medial blade retractor. Once the anterolateral disc surface is visualized, prevertebral soft tissue is gently dissected by cotton pads mounted on long forceps. This step, using gentle blunt dissection, is important to avoid vascular complications. The same accuracy is needed to gently dissect the upper hypogastric plexus, where monopolar coagulation is forbidden and bipolar coagulation is strongly discouraged.

After discectomy and endplate preparation, which represent the most standardized steps in fusion procedures, the cage is filled full of bone substitutes (bovine mineralized bone plus collagen; calcium phosphate granules or paste; and paste of demineralized bone matrix) and positioned in the intersomatic space under fluoroscopic guidance. A titanium standard or oblique interbody cage (Avila-O, Medtronic) and an anterior lumbar plate (PYRAMID, Medtronic) were used in every patient. Cage sizes and lordosis were selected to optimally restore the segmental lordosis and disc height. No intraoperative monitoring was used in any procedure. A drainage device was always left in the retroperitoneal space for 12-24 hours. No external lumbar orthosis devices were prescribed after surgery.

\section{Clinical and Radiological Outcomes}

A 10-point itemized visual analog scale (VAS) for LBP, the Oswestry Disability Index (ODI) questionnaire, and the 

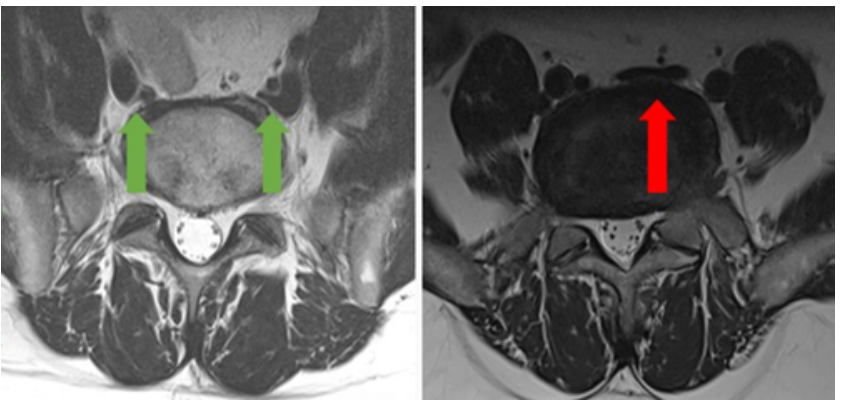

FIG. 1. Axial T2-weighted MRI studies of favorable (left) and unfavorable (right) anatomy of iliac vessels (arrows). In the left panel iliac vessels are laterally located, thus allowing the surgeon to safely approach the anterior profile of the lumbosacral junction. In the right panel a vascular bifurcation is located in front of the lumbosacral junction and a dissection and retraction of the left iliac vein is needed to approach the L5-S1 disc, exposing the patient to a high-risk venous rupture.

36-Item Short Form Health Survey (SF-36) physical and mental component scales were collected preoperatively, 6 weeks after surgery, and at last follow-up. The spinopelvic parameters (lumbar lordosis, L5-S1 segmental lordosis, PI-LL mismatch, sacral slope, pelvic tilt, disc height, and foraminal height); segmental stability; vascular anatomy; and relations of the left common iliac vein with the L5-S1 segment were evaluated on standard and dynamic radiographs, MRI, and CT scans, respectively. According to the vascular anatomy, patients were considered as suitable for surgery only in cases in which the iliac veins' bifurcation was widely open over the disc space (Fig. 1).

Interbody fusion, considered as the presence of cancellous-bone bridges between the contiguous vertebrae of the treated segments, with no further evidence of cortical rims, was evaluated on thin-slice CT scans in all patients 12 months after surgery. The radiological evaluation of images was performed by a single senior radiologist.

Segmental stability was considered as no evidence of residual segmental mobility on dynamic radiographs. Intraoperative and perioperative complications were collected. Postoperative neurological deficits were considered as minor or major complications according to their duration: $\leq 3$ months or $>3$ months, respectively.

\section{Statistical Analysis}

Statistical comparison of continuous variables was performed by the Student t-test. Statistical comparison of categorical variables was performed using the Fisher exact test (chi-square, 2 sides). An alpha value of 0.05 was set for significance. Statistical analyses were conducted using StatView version 5 software (SAS Institute, Inc.).

\section{Results}

\section{Patient Characteristics and Surgical Data}

Thirty-two patients matched the inclusion criteria and were included in the present study. There were $14(43.8 \%)$ women and $18(56.2 \%)$ men, the mean age at the time of surgery was 57.6 years (range $44-75$ years), and the mean follow-up was 33.1 months (range 13-48 months). All pa-
TABLE 1. Characteristics in 32 patients with interbody fusion

\begin{tabular}{|c|c|}
\hline Characteristic & Value \\
\hline Total no. of patients & 32 \\
\hline Mean age, yrs (range) & $57.6(44-75)$ \\
\hline Mean follow-up, mos (range) & $33.1(13-48)$ \\
\hline \multicolumn{2}{|l|}{ Sex, $n(\%)$} \\
\hline Female & $14(43.8 \%)$ \\
\hline Male & $18(56.2 \%)$ \\
\hline \multicolumn{2}{|l|}{ ASA classification, $n(\%)$} \\
\hline 1 & $4(12.5 \%)$ \\
\hline II & $12(37.5 \%)$ \\
\hline III & $15(46.9 \%)$ \\
\hline IV & $1(3.1 \%)$ \\
\hline V & 0 \\
\hline \multicolumn{2}{|l|}{ Clinical presentation, $\mathrm{n}(\%)$} \\
\hline Low-back pain & $32(100 \%)$ \\
\hline Radiculopathy & $18(56.3 \%)$ \\
\hline Neurogenic claudication & $10(31.2 \%)$ \\
\hline Lower-extremity weakness & $1(3.1 \%)$ \\
\hline \multicolumn{2}{|l|}{ Comorbidity, n (\%) } \\
\hline Cardiovascular diseases & $20(62.5 \%)$ \\
\hline Diabetes mellitus & $14(43.8 \%)$ \\
\hline Obesity & $9(28.1 \%)$ \\
\hline Respiratory disease & $6(18.8 \%)$ \\
\hline Smokers & $13(40.6 \%)$ \\
\hline Mean Charlson Comorbidity Index & 2.1 \\
\hline
\end{tabular}

ASA = American Society of Anesthesiologists.

Patients may have multiple clinical presentations and comorbidities.

tients reported LBP preoperatively, whereas radiculopathy was found in 18 patients (56.3\%), neurogenic claudication in $10(31.2 \%)$, and lower-extremity weakness in 1 (3.1\%). The most common comorbidity was cardiovascular diseases $(62.5 \%)$, followed by diabetes mellitus (43.8\%), obesity $(28.1 \%)$, and respiratory diseases (18.8\%). Thirteen patients (40.6\%) were smokers. The mean Charlson Comorbidity Index was 2.1. Four patients had American Society of Anesthesiologists class I (12.5\%), whereas 12 (37.5\%), 15 (46.9\%), and 1 (3.1\%) had class II, III, and IV, respectively.

Group A consisted of 23 patients: foraminal stenosis was found in 11 (47.8\%), grade I spondylolisthesis in 7 (30.4\%), and segmental kyphosis in 5 (21.7\%). Group B consisted of 9 patients, who had undergone a previous posterior thoracolumbar or lumbar fusion, not including the L5-S1 segment. The mean length of surgery was 65 minutes (range 55-100 minutes), the mean intraoperative blood loss was $52 \mathrm{ml}$ (range 40-80 ml), and the mean length of hospitalization was 2 days (range 1-3 days). The cage sizes were $10 \times 27 \times 26.5 \mathrm{~mm}$ with $12^{\circ}$ of lordosis in 25 patients $(78.1 \%)$ and $8 \times 30 \times 29.5 \mathrm{~mm}$ with $8^{\circ}$ of lordosis in 7 $(21.9 \%)$. Every patient was mobilized within 24 hours after surgery. No intraoperative complications were registered. All patients were discharged to home. Patient and operative characteristics are summarized in Tables 1 and 2. 
TABLE 2. Operative characteristics in 32 patients with interbody fusion

\begin{tabular}{cc}
\hline \multicolumn{1}{c}{ Characteristic } & Value \\
\hline Radiological presentation & \\
\hline Group A-DDD, $\mathrm{n}(\%)$ & $23(71.9 \%)$ \\
\hline Foraminal stenosis & $11(47.8 \%)$ \\
\hline Spondylolisthesis & $7(30.4 \%)$ \\
\hline Segmental kyphosis & $5(21.7 \%)$ \\
\hline Group B-revision surgery, $\mathrm{n}(\%)$ & $9(28.1 \%)$ \\
\hline Mean length of surgery, mins (range) & $65(55-100)$ \\
\hline Mean length of hospital stay, days (range) & $2(1-3)$ \\
\hline Mean time of postop mobilization, days (range) & $1(1-4)$ \\
\hline Intraop blood loss, ml (range) & $52(40-80)$ \\
\hline Complication rate, $\mathrm{n}$ (\%) & $1(3.1 \%)$ \\
\hline Superficial wound infection & $1(3.1 \%)$ \\
\hline Incisional pain & $1(3.1 \%)$ \\
\hline Subsidence & $9.4 \%$ \\
\hline Overall complication rate & $1(3.1 \%)$ \\
\hline Reop rate, $\mathrm{n}(\%)$ &
\end{tabular}

Patients may present with multiple radiological features.

TABLE 3. Clinical outcomes in 32 patients with interbody fusion

\begin{tabular}{cc}
\hline Scale \& Time Frame & Mean Score \pm SD \\
\hline VAS & \\
\hline Preop & $7.9 \pm 1.3$ \\
\hline Postop (6 wks) & $3.0 \pm 1.0$ \\
\hline Follow-up & $2.4 \pm 0.8$ \\
\hline p value (preop vs follow-up) & $<0.05$ \\
\hline ODI & $52.8 \pm 14.4$ \\
\hline Preop & $27.2 \pm 7.1$ \\
\hline Postop (6 wks) & $22.9 \pm 6.0$ \\
\hline Follow-up & $<0.05$ \\
\hline p value (preop vs follow-up) & \\
\hline SF-36 (physical \& mental) & $37.3 \pm 5.8$ \\
\hline Preop & $63.7 \pm 7.7$ \\
\hline Postop (6 wks) & $69.8 \pm 6.1$ \\
\hline Follow-up & $<0.05$ \\
\hline p value (preop vs follow-up) &
\end{tabular}

Boldface type indicates statistical significance.

\section{Clinical and Radiological Outcomes}

In comparing the preoperative and last follow-up measurements, the mean $( \pm$ SD) VAS score decreased from $7.9( \pm 1.3)$ to $2.4( \pm 0.8)(\mathrm{p}<0.05)$; the mean ODI score decreased from $52.8( \pm 14.4)$ to $22.9( \pm 6.0)(\mathrm{p}<0.05)$; and the mean SF-36 score (physical and mental components) improved from $37.3( \pm 5.8)$ to $69.8( \pm 6.1)(\mathrm{p}<0.05)$. Clinical patient-reported outcomes are summarized in Table 3.

The pre- and postoperative measurements showed that
TABLE 4. Radiological outcomes in 32 patients with interbody fusion

\begin{tabular}{|c|c|}
\hline Parameter & Mean Value \pm SD \\
\hline \multicolumn{2}{|l|}{ Lumbar lordosis, $^{\circ}$} \\
\hline Preop & $-38.6 \pm 7.7$ \\
\hline Postop (6 wks) & $-46.0 \pm 8.1$ \\
\hline Follow-up & $-46.5 \pm 8.2$ \\
\hline$p$ value (preop vs follow-up) & $<0.05$ \\
\hline \multicolumn{2}{|l|}{ L5-S1 segmental lordosis, $^{\circ}$} \\
\hline Preop & $-6.1 \pm 4.8$ \\
\hline Postop (6 wks) & $-12.9 \pm 2.8$ \\
\hline Follow-up & $-13.3 \pm 2.9$ \\
\hline$p$ value (preop vs follow-up) & $<0.05$ \\
\hline \multicolumn{2}{|l|}{ PI-LL mismatch, ${ }^{\circ}$} \\
\hline Preop & $17.0 \pm 6.8$ \\
\hline Postop (6 wks) & $9.4 \pm 3.1$ \\
\hline Follow-up & $9.5 \pm 6.4$ \\
\hline$p$ value (preop vs follow-up) & $<0.05$ \\
\hline \multicolumn{2}{|l|}{ Sacral slope, $^{\circ}$} \\
\hline Preop & $22.5 \pm 7.4$ \\
\hline Postop (6 wks) & $30.6 \pm 6.9$ \\
\hline Follow-up & $29.1 \pm 7.4$ \\
\hline$p$ value (preop vs follow-up) & $<0.05$ \\
\hline \multicolumn{2}{|l|}{ Pelvic tilt, ${ }^{\circ}$} \\
\hline Preop & $33.4 \pm 5.7$ \\
\hline Postop (6 wks) & $25.3 \pm 6.6$ \\
\hline Follow-up & $26.8 \pm 7.9$ \\
\hline$p$ value (preop vs follow-up) & $<0.05$ \\
\hline \multicolumn{2}{|l|}{ Foraminal height, mm } \\
\hline Preop & $14.8 \pm 1.4$ \\
\hline Postop (6 wks) & $18.0 \pm 1.4$ \\
\hline Follow-up & $17.8 \pm 1.1$ \\
\hline$p$ value (preop vs follow-up) & $<0.05$ \\
\hline \multicolumn{2}{|l|}{ Disc height, $\mathrm{mm}$} \\
\hline Preop & $5.4 \pm 1.3$ \\
\hline Postop (6 wks) & $9.2 \pm 0.8$ \\
\hline Follow-up & $9.0 \pm 0.9$ \\
\hline$p$ value (preop vs follow-up) & $<0.05$ \\
\hline Fusion rate, $\mathrm{n}(\%)$ & $31(96.9)$ \\
\hline
\end{tabular}

Boldface type indicates statistical significance.

the mean lumbar lordosis changed from $-38.6^{\circ}\left( \pm 7.7^{\circ}\right)$ to $-46.5^{\circ}\left( \pm 8.2^{\circ}\right)(\mathrm{p}<0.05)$ and the mean L5-S1 segmental lordosis from $-6.1^{\circ}\left( \pm 4.8^{\circ}\right)$ to $-13.3^{\circ}\left( \pm 2.9^{\circ}\right)(\mathrm{p}<$ $0.05)$. The mean PI-LL mismatch decreased from $17.0^{\circ}( \pm$ $\left.6.8^{\circ}\right)$ preoperatively to $9.5^{\circ}\left( \pm 6.4^{\circ}\right)$ at last follow-up (p < $0.05)$, the mean sacral slope increased from $22.5^{\circ}\left( \pm 7.4^{\circ}\right)$ to $29.1^{\circ}\left( \pm 7.4^{\circ}\right)(\mathrm{p}<0.05)$, and the pelvic tilt decreased from $33.4^{\circ}\left( \pm 5.7^{\circ}\right)$ to $26.8^{\circ}\left( \pm 7.9^{\circ}\right)(p<0.05)$. The mean disc height and foraminal height increased from $5.4( \pm 1.3)$ $\mathrm{mm}$ to $9.0( \pm 0.9) \mathrm{mm}(\mathrm{p}<0.05)$ and from $14.8( \pm 1.4)$ $\mathrm{mm}$ to $17.8( \pm 1.1) \mathrm{mm}(\mathrm{p}<0.05)$, respectively. The fusion 

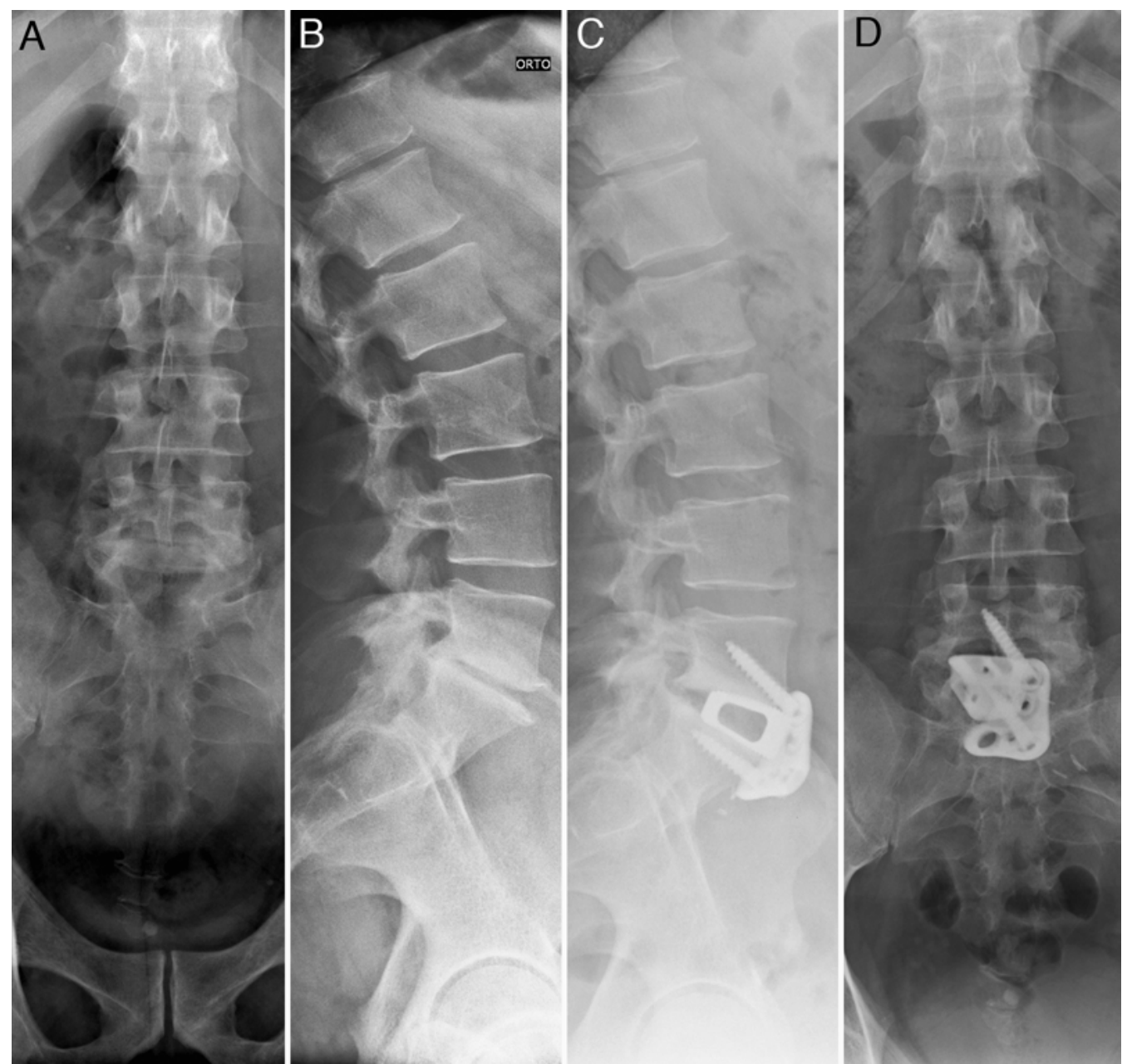

FIG. 2. Illustrative case from group A; preoperative anterior and lateral lumbar radiographs of a 49 -year-old man showing a severe L5-S1 disc degeneration (A and B). The patient underwent a stand-alone OLIF and anterior plating with restoration of lumbar lordosis and intervertebral disc height (C and D).

rate was $96.9 \%$. Radiological outcomes are summarized in Table 4. Illustrative cases from group A and group B are presented in Figs. 2 and 3, respectively. Figure 4 shows fusion as it appears on CT scans at the 12-month follow-up in a patient from group B.

\section{Complications and Reoperation Rate}

No perioperative or postoperative major complications were recorded. Three minor complications (overall complication rate of 9.4\%) were observed: 1 superficial wound infection with complete resolution within 2 weeks; 1 patient with incisional pain treated with medical therapy; and 1 asymptomatic cage subsidence that did not need revision surgery. No long-term complications or implant failure were observed during follow-up. One patient (3.1\%) from group B needed reoperation: this was a 65-year-old man who underwent L5-S1 OLIF 2 years after an L1-5 posterior fixation for correction of deformity. The patient reported persistent right radiculopathy due to residual foraminal stenosis, which required a posterior decompression.

\section{Discussion}

In the last few decades, the preferred management of patients suffering from degenerative spinal conditions has been changing. Elective surgeries have been progressively accepted as the standard treatment in medically resistant cases, and circumferential fusion has been reported as providing valuable clinical and radiological outcomes in those patients selected for instrumentation techniques. ${ }^{1,2}$ Furthermore, anterior and lateral approaches, and especially their minimally invasive surgery alternatives, have become even more popular among spine surgeons. The lumbar spine is now frequently approached from its side or front, although posterior approaches have been historically preferred. Accordingly, spine surgeons are progressively moving around their patients, from the back to the front side. ${ }^{5,6}$

Minimally invasive lateral lumbar interbody fusion (LLIF) is now considered to be a standard approach for degenerative lumbar disorders. ${ }^{24-26}$ Nevertheless, LLIF has some limits that need to be disclosed: neuromoni- 


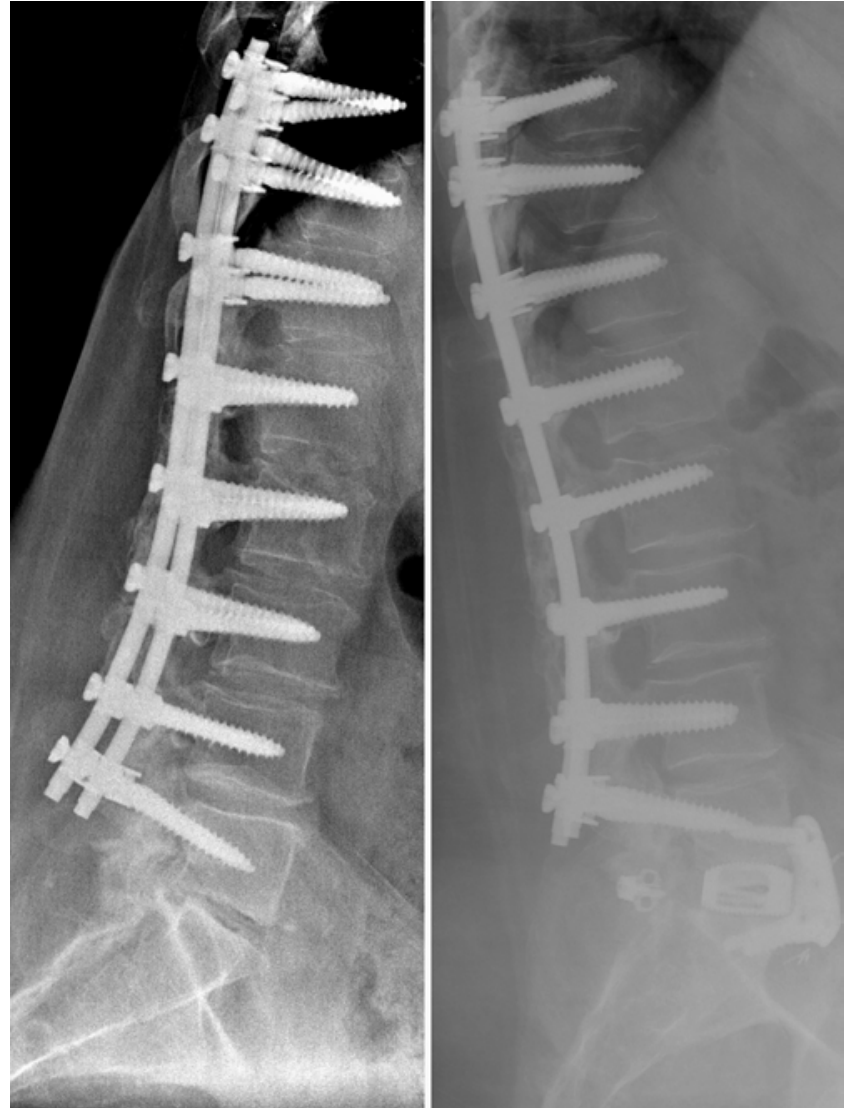

FIG. 3. Illustrative case from group B; a preoperative dynamic lateral lumbar radiograph of a 64-year-old woman showing the uncorrected lumbar kyphotic deformity at L5-S1 after a previous T10-L5 posterior fixation for deformity correction (left). Lateral standing radiograph showing the L5-S1 OLIF and anterior plating. Note that before ATP surgery the patient underwent another unsuccessful surgery for L5-S1 facetwedge positioning (right).

toring is strictly needed due to the nonnegligible risk for nerve root injuries; the procedure cannot be performed at L5-S1 due to the iliac crest projection; and it is burdened by an intrinsic morbidity because of the violation of the psoas muscle. The necessity for aborting this procedure during the psoas transgression, especially for a highly degenerated and rotated L4 -5 segment, is also a commonly reported experience. ${ }^{27-29}$

ATP is a retroperitoneal approach based on dissection of the surgical corridor between the arterial axis (medial) and the psoas tendon (lateral). This corridor has been well described in different anatomical and morphological MRI studies, and it represents a safe path to lumbar discs. ${ }^{30-32}$ Different acronyms have been proposed, such as ATP and OLIF, mainly confusing surgeons, since there are no relevant differences when comparing them. In particular, the terms "ATP," "OLIF," and "lateral ALIF" indeed represent the same surgical approach, from the skin incision to the cage insertion and final plating.

Anterior and anterolateral approaches to L5-S1 have been demonstrated as very effective in the correction of spinal deformities, using wider, higher, and more lordot-

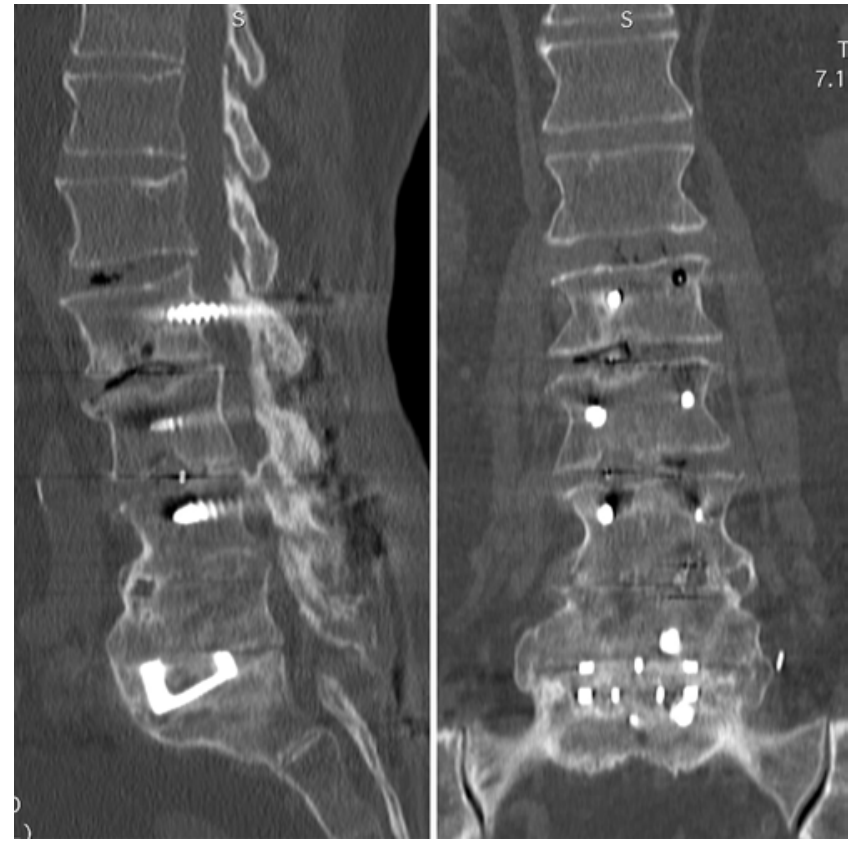

FIG. 4. Illustrative case from group B showing fusion on sagittal (left) and coronal (right) CT scans. Note the presence of cancellous-bone bridges inside the cage and between the contiguous vertebrae of the surgically treated segments.

ic cages compared with those available in posterior approaches. ${ }^{8}$

ALIF and mini-ALIF have been reported as being very effective to restore the lumbar and segmental lordosis on L5-S1. These operations are performed with the patient in the supine Trendelenburg position, using a paraumbilical incision, and then the promontory of the sacrum and the L5-S1 disc space is exposed by gently dissecting the retroperitoneal space, carefully mobilizing the retroperitoneal vessels..$^{34,35}$ These techniques have some limits that need to be discussed: there are anatomical limitations in obese patients; iliac veins might be retracted and potentially injured; and in case a posterior instrumentation is needed, the patient must be flipped for a second stage. ${ }^{21}$ A systematic review by Bateman et al. reported that the most common complications of ALIF were venous injury (3.2\%), retrograde ejaculation (2.7\%), and neurological injury (2\%). ${ }^{22} \mathrm{~A}$ recent study reported that obesity is associated with increased postoperative complications in ALIF, including postoperative ileus, wound complications, and urinary tract infections. ${ }^{36}$ On the other hand, Xi et al. demonstrated that obesity generally does not increase the operative time, blood loss, approach-related sequelae, or complications following OLIF. ${ }^{37}$

ATP is theoretically supposed to reduce the necessity for a wide retroperitoneal dissection, superior hypogastric plexus injuries, and retraction of iliac vessels. The patient is always placed in the right lateral decubitus position, and a small incision in front of the anterior-superior iliac crest allows the surgeon to easily access the retroperitoneal space, medial to the psoas tendon..$^{15}$

In the lateral decubitus position, gravity naturally pro- 
motes dislocation of the abdominal contents downward and forward, far from the anterior column, as a natural retraction. Farah et al., in a recent morphometric MRI study with patients in the right lateral decubitus position, reported that this position with the left hip in extension displaces the vascular structures and reduces the psoas volume. ${ }^{38}$

A left-sided approach is generally preferred, to avoid the possible retraction of the inferior vena cava. Similarly to ALIF, L5-S1 is approached via the 2 iliac axes, below the aortic bifurcation. The L5-S1 disc is approached anterolaterally, rather than frontally as in ALIF; therefore, a standard ALIF cage or a properly designed oblique one can be positioned between the 2 contiguous vertebrae after discectomy and preparation of the endplates.

Several studies have reported that the ATP approach is associated with low risk for retrograde ejaculation, vascular injury, and motor weakness, because of the lower need for retroperitoneal dissection and retraction. ${ }^{22,33}$ However, comparing historical complication rates requires careful interpretation, and comparative studies are not available yet.

Specific limits on ATP should be disclosed: in case of high-grade spondylolisthesis, the iliac crest may impede the optimal control of the segment; the vascular anatomy should be carefully investigated preoperatively to avoid potential intraoperative hemorrhages; and previous abdominal surgeries may be considered as relative contraindications.

Our results seem to confirm that ATP can be considered as an effective procedure at L5-S1, with high fusion rates. No major intra- or perioperative complications have been recorded in the present case series. One patient (3.1\%) needed a posterior revision surgery due to residual foraminal stenosis and persistent radiculopathy. We do not report any vascular injury, probably due to our previous experience in lateral, anterolateral, and anterior approaches to the lumbar spine. ${ }^{26}$

All patients of this series have been operated on by the two senior surgeons, without the need for an access surgeon, who nevertheless always remained available in case of need. Therefore, the reported outcomes may not reveal the early learning phase of the ATP approach. The literature seems to confirm that the use of an access surgeon in anterior approaches for lumbar arthrodesis is associated with similar intraoperative complication rates compared with procedures with no access surgeon..$^{39}$

Nonetheless, in our opinion, the preoperative planning represents the most relevant factor in reducing the risk for the aforementioned complications. We carefully evaluate the local anatomy on preoperative imaging, especially axial MRI scans, defining whether an ATP approach is suitable for the patient according to the course of the left iliac vein and its relation with the disc space (Fig. 1). The superior hypogastric plexus was never injured in these patients, probably due to the minimal retroperitoneal dissection and the lower need for the use of bipolar forceps, with their potential to cause thermal damage to the tiny fibers.

The anterior plating was also used in every patient, and it is our opinion that this is even more useful at L5-S1, due to the wider cages we may use at this level, and the systematic section of the anterior longitudinal ligament.
The surgical duration, intraoperative blood loss, and length of hospitalization are comparable to those reported for lateral and anterior approaches. The clinical-radiological outcomes are valuable in this relatively small cohort of patients. This technique and the cages to insert in the disc space allow the surgeon to effectively restore the segmental lordosis, thus providing results that are tremendously useful in deformity and revision surgeries.

\section{Limitations of the Study}

There are some limitations to be disclosed. The patient sample is relatively small and, consequently, some complications and effects could have been unrecognized. The follow-up length could have been too short for reporting long-term implant-related complications. According to the study design, there was not a control group, and the level of evidence should be evaluated accordingly, for a proper interpretation of data.

\section{Conclusions}

ATP at the L5-S1 segment provides valuable clinical and radiological outcomes. It is associated with a relatively low complication rate that is similar to those of other anterior approaches. Accurate evaluation of vascular anatomy on preoperative images and a steep learning curve are mandatory to avoid approach-related complications. Properly designed clinical studies with longer follow-up are needed to evaluate the role of ATP in L5-S1 surgeries.

\section{References}

1. Cowan JA Jr, Dimick JB, Wainess R, et al. Changes in the utilization of spinal fusion in the United States. Neurosurgery. 2006;59(1):15-20.

2. Yavin D, Casha S, Wiebe S, et al. Lumbar fusion for degenerative disease: a systematic review and meta-analysis. Neurosurgery. 2017;80(5):701-715.

3. Martin BI, Mirza SK, Spina N, et al. Trends in lumbar fusion procedure rates and associated hospital costs for degenerative spinal diseases in the United States, 2004 to 2015. Spine (Phila Pa 1976). 2019;44(5):369-376.

4. Mobbs RJ, Phan K, Malham G, et al. Lumbar interbody fusion: techniques, indications and comparison of interbody fusion options including PLIF, TLIF, MI-TLIF, OLIF/ATP, LLIF and ALIF. J Spine Surg. 2015;1(1):2-18.

5. Xu DS, Walker CT, Godzik J, et al. Minimally invasive anterior, lateral, and oblique lumbar interbody fusion: a literature review. Ann Transl Med. 2018;6(6):104.

6. Wewel JT, Godzik J, Uribe JS. The utilization of minimally invasive surgery techniques for the treatment of spinal deformity. J Spine Surg. 2019;5(1)(suppl 1):S84-S90.

7. Wang MY, Tran S, Brusko GD, et al. Less invasive spinal deformity surgery: the impact of the learning curve at tertiary spine care centers. J Neurosurg Spine. 2019;31(6):865-872.

8. Rothrock RJ, McNeill IT, Yaeger K, et al. Lumbar lordosis correction with interbody fusion: systematic literature review and analysis. World Neurosurg. 2018;118:21-31.

9. Ricciardi L, Stifano V, Proietti L, et al. Intraoperative and postoperative segmental lordosis mismatch: analysis of $3 \mathrm{fu}-$ sion techniques. World Neurosurg. 2018;115:e659-e663.

10. Bae J, Theologis AA, Strom R, et al. Comparative analysis of 3 surgical strategies for adult spinal deformity with mild to moderate sagittal imbalance. J Neurosurg Spine. 2018;28(1): 40-49. 
11. Ahlquist S, Park HY, Gatto J, et al. Does approach matter? A comparative radiographic analysis of spinopelvic parameters in single-level lumbar fusion. Spine J. 2018;18(11):19992008.

12. Mayer HM. A new microsurgical technique for minimally invasive anterior lumbar interbody fusion. Spine (Phila Pa 1976). 1997;22(6):691-700.

13. Silvestre C, Mac-Thiong J-M, Hilmi R, Roussouly P. Complications and morbidities of mini-open anterior retroperitoneal lumbar interbody fusion: oblique lumbar interbody fusion in 179 patients. Asian Spine J. 2012;6(2):89-97.

14. Abe K, Orita S, Mannoji C, et al. Perioperative complications in 155 patients who underwent oblique lateral interbody fusion surgery: perspectives and indications from a retrospective, multicenter survey. Spine (Phila Pa 1976). 2017;42(1): $55-62$.

15. Li JX, Phan K, Mobbs R. Oblique lumbar interbody fusion: technical aspects, operative outcomes, and complications. World Neurosurg. 2017;98:113-123.

16. Mehren C, Korge A. Minimally invasive anterior oblique lumbar interbody fusion (OLIF). Eur Spine J. 2016;25(4) (suppl 4):471-472.

17. Woods KR, Billys JB, Hynes RA. Technical description of oblique lateral interbody fusion at L1-L5 (OLIF25) and at L5-S1 (OLIF51) and evaluation of complication and fusion rates. Spine J. 2017;17(4):545-553.

18. Liu C, Wang J, Zhou Y. Perioperative complications associated with minimally invasive surgery of oblique lumbar interbody fusions for degenerative lumbar diseases in 113 patients. Clin Neurol Neurosurg. 2019;184:105381.

19. Fujibayashi S, Hynes RA, Otsuki B, et al. Effect of indirect neural decompression through oblique lateral interbody fusion for degenerative lumbar disease. Spine (Phila Pa 1976). 2015;40(3):E175-E182.

20. Kim JS, Sharma SB. How I do it? Oblique lumbar interbody fusion at L5S1(OLIF51). Acta Neurochir (Wien). 2019;161(6): 1079-1083.

21. Than KD, Wang AC, Rahman SU, et al. Complication avoidance and management in anterior lumbar interbody fusion. Neurosurg Focus. 2011;31(4):E6.

22. Bateman DK, Millhouse PW, Shahi N, et al. Anterior lumbar spine surgery: a systematic review and meta-analysis of associated complications. Spine J. 2015;15(5):1118-1132.

23. Meyerding HW. Spondylolisthesis; surgical fusion of lumbosacral portion of spinal column and interarticular facets; use of autogenous bone grafts for relief of disabling backache. $J$ Int Coll Surg. 1956;26(5 Part 1):566-591.

24. Ozgur BM, Aryan HE, Pimenta L, Taylor WR. Extreme Lateral Interbody Fusion (XLIF): a novel surgical technique for anterior lumbar interbody fusion. Spine J. 2006;6(4):435-443.

25. Keorochana G, Setrkraising K, Woratanarat P, et al. Clinical outcomes after minimally invasive transforaminal lumbar interbody fusion and lateral lumbar interbody fusion for treatment of degenerative lumbar disease: a systematic review and meta-analysis. Neurosurg Rev. 2018;41(3):755-770.

26. Miscusi M, Ramieri A, Forcato S, et al. Comparison of pure lateral and oblique lateral inter-body fusion for treatment of lumbar degenerative disk disease: a multicentric cohort study. Eur Spine J. 2018;27(2)(suppl 2):222-228.

27. Hijji FY, Narain AS, Bohl DD, et al. Lateral lumbar interbody fusion: a systematic review of complication rates. Spine J. 2017;17(10):1412-1419.

28. Epstein NE. Review of risks and complications of extreme lateral interbody fusion (XLIF). Surg Neurol Int. 2019;10: 237.

29. Walker CT, Farber SH, Cole TS, et al. Complications for minimally invasive lateral interbody arthrodesis: a systematic review and meta-analysis comparing prepsoas and transpsoas approaches. J Neurosurg Spine. 2019;30(4):446-460.
30. Deukmedjian AR, Le TV, Dakwar E, et al. Movement of abdominal structures on magnetic resonance imaging during positioning changes related to lateral lumbar spine surgery: a morphometric study: clinical article. J Neurosurg Spine. 2012;16(6):615-623.

31. Molinares DM, Davis TT, Fung DA. Retroperitoneal oblique corridor to the L2-S1 intervertebral discs: an MRI study. $J$ Neurosurg Spine. 2016;24(2):248-255.

32. Davis TT, Hynes RA, Fung DA, et al. Retroperitoneal oblique corridor to the L2-S1 intervertebral discs in the lateral position: an anatomic study. J Neurosurg Spine. 2014;21(5): 785-793.

33. Tannoury T, Kempegowda H, Haddadi K, Tannoury C. Complications associated with minimally invasive anterior to the psoas (ATP) fusion of the lumbosacral spine. Spine (Phila $\mathrm{Pa}$ 1976). 2019;44(19):E1122-E1129.

34. Brau SA. Mini-open approach to the spine for anterior lumbar interbody fusion: description of the procedure, results and complications. Spine J. 2002;2(3):216-223.

35. Bassani R, Querenghi AM, Cecchinato R, et al. A new "keyhole" approach for multilevel anterior lumbar interbody fusion: the perinavel approach-technical note and literature review. Eur Spine J. 2018;27(8):1956-1963.

36. Safaee MM, Tenorio A, Osorio JA, et al. The impact of obesity on perioperative complications in patients undergoing anterior lumbar interbody fusion. J Neurosurg Spine. 2020;33(3):332-341.

37. Xi Z, Burch S, Mummaneni PV, et al. The effect of obesity on perioperative morbidity in oblique lumbar interbody fusion. J Neurosurg Spine. 2020;33(2):203-210.

38. Farah K, Leroy HA, Karnoub MA, et al. Does the hip positioning matter for oblique lumbar interbody fusion approach? A morphometric study. Eur Spine J. 2020;29(2):306-313.

39. Phan K, Xu J, Scherman DB, et al. Anterior lumbar interbody fusion with and without an "access surgeon": a systematic review and meta-analysis. Spine (Phila Pa 1976). 2017;42(10): E592-E601.

\section{Disclosures}

The authors report no conflict of interest concerning the materials or methods used in this study or the findings specified in this paper.

\section{Author Contributions}

Conception and design: Trungu, Miscusi, Raco. Acquisition of data: Trungu, Ricciardi. Analysis and interpretation of data: Trungu, Miscusi, Ricciardi, Forcato, Ramieri. Drafting the article: Trungu, Miscusi, Ricciardi. Critically revising the article: Miscusi, Forcato, Ramieri, Raco. Reviewed submitted version of manuscript: Ricciardi. Approved the final version of the manuscript on behalf of all authors: Trungu. Statistical analysis: Forcato. Administrative/technical/material support: Ramieri. Study supervision: Miscusi, Raco.

\section{Supplemental Information \\ Videos \\ Video Abstract. https://vimeo.com/446476838.}

\section{Correspondence}

Sokol Trungu: Cardinal G. Panico Hospital, Tricase, Italy. s_trungu@hotmail.com. 